\title{
MODELO MATEMÁTICO PARA POSTERGAÇÃO DE TEMPO NO PROJETO DE REDE LOGÍSTICA REVERSA COM NÍVEIS DE CAPACIDADE
}

\section{MATHEMATICAL MODELLING FOR TIME POSTPONEMENT IN REVERSE NETWORK LOGISTIC DESIGN WITH CAPACITY LEVELS}

\author{
Marcos Wagner Jesus Servare Junior ${ }^{1 *}$, \& Patrícia Alcântara Cardoso² \\ 12 Programa de Pós-Graduação em Engenharia Civil do Centro Tecnológico da Universidade Federal do Espírito \\ Santo, Av. Fernando Ferrari, 514 - Goiabeiras, Vitória - ES, CEP 29075-910. \\ 1*marcoswjunior@gmail.com ${ }^{2}$ patricia.cardoso@ufes.br
}

\section{ARTIGO INFO.}

Recebido em: 04.09.2020

Aprovado em: 28.09.2020

Disponibilizado em: 09.10.2020

Palavras-chave:

Postergação de Tempo; Logística Reversa; Projeto de Rede Logística Reversa; Modelagem Matemática; Óleo de Cozinha Usado.

\section{KEYWORDS:}

Time Postponement; Reverse logistic; Reverse Logistic Network Design; Mathematical Modeling; Used Cooking Oil.

*Autor Correspondente: Servare Junior, M. W. J.

\section{RESUMO}

Uma questão crucial no projeto de eficientes sistemas logísticos é a identificação de locais para instalações dos estoques. Em paralelo a isso, o crescimento mundial do consumo de produtos ocasiona $\mathrm{O}$ surgimento de uma preocupação acerca do fim da vida útil ou o fim do consumo destes produtos uma vez que seu descarte inapropriado pode provocar problemas ambientais graves. O descarte do óleo usado é uma destas situações, que quando descartado de forma inapropriada pode acarretar um severo impacto ambiental em uma região. Neste artigo, para é analisado o problema de postergação de tempo e propõe uma modelagem matemática para utilização da postergação de tempo no projeto da cadeia de suprimentos reversa, com validação do seu uso com a aplicação no sistema logístico reverso do óleo de cozinha em Vitória a partir de cenários para avaliação da técnica e, então, solucionar de maneira eficiente e ótima o problema com a implementação no solver comercial CPLEX 12.6.

\begin{abstract}
A crucial issue in the design of efficient logistics systems is the locations for inventory. In parallel to this, the worldwide growth in the consumption of products causes the emergence of a concern about the end of the useful life or the end of the consumption of these products since their inappropriate disposal can cause serious environmental problems. The disposal of used cooking oil is one of these situations, which when improperly disposed of can have a severe environmental impact in a region. In this paper, the time postponement problem is analyzed and was proposed a mathematical modeling for the use of time postponement in the reverse supply chain design, with validation of its use with the application in the reverse logistics system of cooking oil in Vitória from scenarios to evaluate the technique and then solve efficiently e with an optimal solution the problem with the implementation in CPLEX 12.6.
\end{abstract}




\section{INTRODUÇão}

A logística tem fundamental nas relações comerciais e suas influências em custos e participações implicam em importante parcela no planejamento gerencial e tomada de decisão empresarial.Com isso, as exigências do mercado não se resumem em apenas levar e trazer mercadorias, é necessária a realização de um planejamento em termos de atendimento a demanda (Porto, 2011). Logo, o acesso ao produto certo é o principal objetivo destas operações, ou seja, entregue ao cliente, no momento certo, e no local designado, porém, com maior agilidade e segurança.

Neste contexto, Alderson (1950) apresentou o princípio da postergação como alternativa do marketing para auxiliar neste processo. O princípio recomenda uma postergação, ou atraso, na movimentação física e na configuração do produto quanto for possível nos processos de produção e distribuição dos produtos. De maneira específica, o autor ainda sugere que postergar a movimentação de um produto no processo de distribuição física seja tratado como postergação de tempo.

Neste trabalho, a cadeia de suprimentos projetada foi a cadeia reversa do óleo de cozinha usado, que tem sido objeto de discussões em diversos trabalhos na literatura. Dentre os fatores que impactam no desenvolvimento desse tipo de pesquisa é a crescente observação dos aspectos ambientais pelos legisladores, a partir de leis que estimulem a preservação e o controle da produção de resíduos e poluentes (Jabali, et al., 2012), dentre elas a Lei 12.305 de 2010 (Brasil, 2010), que instituiu a Política Nacional de Resíduos Sólidos (PNRS), situação que vem motivando ainda mais as pesquisas na área de logística reversa. Especificamente, no munícipio de Vitória, ES o Projeto de Lei 308 de 2014 (Vitória, 2014a) estabelece a obrigatoriedade de supermercados com mais de $50 \mathrm{~m} 2$ de manter em seu estabelecimento um recipiente para receber óleo descartado.

Essa lei caracteriza obrigações a nível organizacional, municipal, regional, estadual e nacional para que seja dado um fim adequado aos resíduos produzidos, atribuindo e compartilhando as responsabilidades do ciclo de vida do produto ao fabricante, importador, distribuidor e comerciante que disponibilizam o produto aos consumidores.

Ainda, mediante a crise hídrica vivida pela região nos últimos anos, um fator de destaque na motivação desse estudo é a questão ambiental, uma vez que um litro de óleo pode poluir 20 mil litros de água (Brasil, 2014). Essa estimativa implica que um destino inadequado para todo óleo consumido na região metropolitana pode gerar um acidente ambiental muito elevado.

Diante do exposto, com a motivação destas duas importantes áreas - logística reversa e postergação de tempo, esta pesquisa foi desenvolvida de modo a sugerir uma alternativa de estruturação da rede logística reversa para o óleo de cozinha usado e como objeto de aplicação foi implementado um modelo matemático para um estudo de caso real no município de Vitória no estado do Espírito Santo.

\section{REVISÃO DE LITERATURA}

\subsection{PRINCíPIO da POSTERGaÇão}

O princípio da postergação foi introduzido na literatura por Alderson (1950) como uma ferramenta para auxílio na gestão e realização do gerenciamento de risco. Ainda sendo este 

logística reversa com níveis de capacidade. Brazilian Journal of Production Engineering, 6(7), 1-22.

princípio definido como um ordenamento nas etapas de geração de valor nos processos relacionados ao marketing e a manufatura com a mudança de forma, identidade ou lugar acontecendo no instante mais tardio que for possível.

Assim, a postergação na movimentação do produto no canal de distribuição foi denominada postergação de tempo (do inglês, time postponement), enquanto a postergação na diferenciação de um produto foi chamada de postergação de forma (do inglês, form postponement).

Para concluir a delimitação desta área de estudo Bucklin (1965) apresentou o princípio da especulação. Nesta alternativa, as empresas apontam a não utilização da postergação na cadeia de suprimentos e o risco e o estoque vão estar amplamente concentrados no varejo, em discordância ao que é proposto no princípio da postergação.

Para García-Dastugue e Lambert (2007), a postergação baseada no tempo consiste no atraso da movimentação do produto adiante na cadeia de suprimentos e, então, gerando um acúmulo de produtos, ou seja, uma formação de estoque. Servare Junior e Cardoso (2016) apresentam uma revisão sobre os trabalhos de modelos matemáticos para postergação de tempo na cadeia de suprimentos a partir de 1996.

Os modelos matemáticos para projetos de redes logísticas com postergação de tempo que foram observados na literatura pelos autores são descritos a seguir.

O primeiro deles é o artigo de Lau e Lau (1996), onde apresentam uma formulação para minimizar o custo total esperado de $\mathrm{N}$ produtos sujeita a um limite de capacidade. Como técnica de solução utilizaram um procedimento de multiplicação Lagrangeana e, em seguida, aplicaram uma heurística.

Por sua vez, Das e Tiagy (1997) apresentam um modelo resolvido por técnicas exatas que busca uma solução para o trade-off entre os três papéis de um estoque: o estoque cíclico, o estoque de segurança, e a distribuição do estoque, sujeito ao cumprimento dos requisitos de serviço ao cliente. A aplicação do estudo foi em 8 zonas de clientes e 3 instalações na região sudeste dos Estados Unidos, com dados obtidos de fontes secundárias. A implementação do modelo indica o grau de centralização dos estoques em cada cenário proposto. São sugeridos e solucionados 5 cenários que variam, entre eles, as características da formulação de custos do modelo.

Eynan (1999) demonstra que a alocação de estoque para os dois locais é independente do tempo $\mathrm{t}$ permite expressar a função de lucro sem a necessidade de especificar o momento em que a empresa esgote o seu inventário. Além disso, mostra que este problema de localização com duas camadas pode ser reduzido a um problema de localização.

Nozick e Turnquist (2001) propõem um modelo de minimização de dois objetivos, resolvendo através da adoção de pesos para balanceamento da Funçao Objetivo. Os objetivos que se deseja minimizar são os custos de instalação de um estoque em determinada localidade e a não cobertura de uma região, ocasionando o não atendimento da demanda. O modelo por sugerido é aplicado em um estudo de caso da indústria automotiva dos Estados Unidos, com 698 zonas consumidoras

O modelo apresentado por Aviv e Ferdegruen (2001) consideram um problema de alocação míope, ou seja, um problema de alocação com entrada de ordem de um produto para 

logística reversa com níveis de capacidade. Brazilian Journal of Production Engineering, 6(7), 1-22.

minimização dos custos esperados no primeiro instante e que tenha impactos em momentos posteriores; isto é, 1 períodos mais tarde.

Gaur e Ravindran (2006) apresentam um problema que envolve os riscos de decisões atribuídas aos armazéns (Centros de Distribuição) para zonas de clientes (varejos) e as políticas de estoque nos armazéns, a fim de minimizar o custo total do sistema e maximizar a disponibilidade do produto/nível de serviço do sistema. Para resolver, os autores utilizam dois solvers comerciais para resolução do modelo através um algoritmo que utiliza os solvers para execução de etapas propostas.

Garcia-Dastugue e Lambert (2007) implementam o modelo de Graves e Willens (2000) e utilizam técnicas exatas para solucionar o modelo nas instancias apontadas.

Kutanoglu e Lohyia (2008) apresentam uma formulação para seleção da política de estoques e modo de transportes para reposição de peças, considerando o nível de serviço baseado no tempo. Os autores resolveram o modelo para casos de uma instalação e três instalações com a linguagem de modelagem GAMS em conjunto com o CPLEX para as instancias geradas.

O problema apresentado por Razmi, Zahedi-Anaraki e Zakerinia (2013) é a respeito de um produto único e período único. Visando a adoção de múltiplos cenários, foi proposto um sistema com um conjunto de plantas com um dado nível de produção, um conjunto de depósitos potenciais disponíveis e zonas dos clientes pré-determinados. Há um conjunto de cenários com um determinado.

A técnica de solução usada foi a partir da implementação o algoritmo de sistema geral de modelagem algébrica (GAMS) em conjunto com o solver CPLEX para encontrar a solução do modelo no cenário proposto, que se trata de um estudo de caso de uma empresa de distribuição farmacêutica em Teerã, capital do Irã com uma a rede de distribuição que contém 2 fábricas, 6 armazéns disponíveis e 20 zonas consumidoras de tal forma que as fábricas produzem as drogas, enviam para os armazéns e, finalmente, as entregam aos clientes

No que concerne a Çelebi (2015), foi realizado a solução com o uso de uma meta heurística, o Algoritmo Genético, para um modelo com uma FO de minimização dos custos totais do sistema. Por fim, Servare Junior, et al., (2018) propõem um modelo matemático de Programação NãoLinear Inteira Mista para um estudo de localização de estoque em um Projeto de Cadeia de Suprimentos com Postergação de Tempo com simulação dos parâmetros para teste e validação para instâncias solucionadas com técnicas exatas.

De maneira geral, os problemas de postergação de tempo que foram abordados neste trabalho podem ser observados com suas principais características de maneira resumida nas Quadro 1, com a nomenclatura a respeito da classificação dos trabalhos e Quadro 2 como cada trabalho foi classificado segundo estas características. 

logística reversa com níveis de capacidade. Brazilian Journal of Production Engineering, 6(7), 1-22.

Quadro 1. Classificação dos problemas de postergação de tempo

\begin{tabular}{|c|c|c|c|}
\hline Objetivo & & Definição do Problema & \\
\hline Maximizar Nível de Serviço & Res & Período & \\
\hline Minimizar Custo/Maximizar Lucro & $\mathrm{C}$ & Multi-períodos & MPr \\
\hline \multirow[t]{2}{*}{ Maximizar Cobertura } & $\mathrm{Cb}$ & Período único & $\mathrm{SPr}$ \\
\hline & & Número de instalações abertas & \\
\hline Saídas & & Indeterminado & Em \\
\hline Estoque & I & Determinado & Ex \\
\hline Quantidade da ordem & Q & Produto & \\
\hline Quantidade transportada & TA & Único & $\mathrm{SP}$ \\
\hline Localização de Instalação & $\mathrm{L}$ & Multi produtos & MP \\
\hline Localização de Produto & LP & Fluxo transportado & \\
\hline Ponto de reabastecimento & PR & Sem capacidade & $\mathrm{UCF}$ \\
\hline Tempo de Serviço & ST & Com capacidade & $\mathrm{CF}$ \\
\hline Modo de Transporte & Md & Demanda & \\
\hline Custo & $\mathrm{Ct}$ & Estocástica & $\mathrm{S}$ \\
\hline Capacidade & $\mathrm{Cp}$ & Determinística & $\mathrm{D}$ \\
\hline \multirow[t]{2}{*}{ Satisfação da Demanda } & DS & Capacidade de Instalação & \\
\hline & & Sem capacidade & $\mathrm{UC}$ \\
\hline Modelagem & & Com capacidade & $\mathrm{Ca}$ \\
\hline Programação dinâmica & $\mathrm{DP}$ & & \\
\hline Programação não-linear Inteira Mista & MINLP & & \\
\hline Programação Linear Inteira Mista & MILP & & \\
\hline Programação Estocástica Inteira Mista & SMIP & & \\
\hline
\end{tabular}

Quadro 2. Codificação dos artigos revisados sobre postergação de tempo.

\begin{tabular}{|c|c|c|c|c|c|}
\hline Artigo & Definição do Problema & Modelagem & Saídas & Objetivos & $\begin{array}{l}\text { Método de } \\
\text { Solução }\end{array}$ \\
\hline Lau, \& Lau (1996) & SPr; En; MP; UCF; UC; D & MINLP & $\mathrm{Q}$ & $\mathrm{C}$ & Heurística \\
\hline Das, \& Tiagy (1997) & SPr; En; SP; UCF; UC; D & MINLP & TA & $\mathrm{C}$ & Heurística \\
\hline Eynan (1999) & SPr; En; SP; UCF; UC; S & MILP & I & $\mathrm{C}$ & Exato \\
\hline $\begin{array}{l}\text { Nozick \& Turnquist } \\
\text { (2001) }\end{array}$ & Spr; En; SP; UCF; UC; D & MILP & $\mathrm{TA} ; \mathrm{L}$ & $\mathrm{C}$ & Exato \\
\hline $\begin{array}{l}\text { Aviv, \& Ferdegruen } \\
\text { (2001) }\end{array}$ & Mpr; En; MP; UCF; UC; S & DP & LP & $\mathrm{C}$ & \\
\hline $\begin{array}{c}\text { Gaur, \& Ravindran } \\
\text { (2006) }\end{array}$ & SPr; En; SP; UCF; Ca; D & MINLP & $\begin{array}{l}\text { TA; L; Q; } \\
\quad \text { PR }\end{array}$ & C; Res & Heurística \\
\hline $\begin{array}{l}\text { Garcia-Dastugue, \& } \\
\text { Lambert (2007) }\end{array}$ & MPr; En; SP; UCF; UC; D & MILP & ST & $\mathrm{C}$ & Exato \\
\hline $\begin{array}{l}\text { Kutanoglu, \& Lohyia } \\
\qquad(2008)\end{array}$ & MPr; En; MP; UCF; UC; D & MINLP & $\mathrm{I} ; \mathrm{Md} ; \mathrm{DS}$ & $\mathrm{C}$ & Heurística \\
\hline $\begin{array}{c}\text { Razmi, Zahedi- } \\
\text { Anaraki, \& Zakerinia } \\
\text { (2013) }\end{array}$ & SPr; Ex; SP; UCF; Ca; S & SMIP & $\begin{array}{l}\mathrm{TA} ; \mathrm{L} ; \mathrm{Ct} ; \\
\mathrm{Cp}\end{array}$ & $\mathrm{C} ; \mathrm{Cb}$ & Heurística \\
\hline Çelebi (2015) & MPr; Ex; SP; UCF; Ca; D & MILP & I & $\mathrm{C}$ & GA \\
\hline $\begin{array}{l}\text { Servare Junior, et al., } \\
(2018)\end{array}$ & SPr; Ex; SP; UCF; UC; D & MINLP & I; TA. L; Ct & $\mathrm{C}$ & Exato \\
\hline
\end{tabular}

Fonte: Adaptado de Servare Junior, et al., (2018)

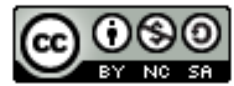



logística reversa com níveis de capacidade. Brazilian Journal of Production Engineering, 6(7), 1-22.

Uma importante constatação que os trabalhos apresentam o estudo da postergação de tempo para projeto de redes logísticas diretas, ou seja, trabalham com o abastecimento e distribuição dos produtos aos clientes.

\subsection{LOGÍSTICA REVERSA}

Embora se trate de um conceito relativamente recente na literatura, De Brito e Dekker (2004) destacam que a logística reversa está presente a algum tempo na literatura, com trabalhos que tratam desta área de conhecimento com outras nomenclaturas que em sua essência convergem à definição de um estudo de logística reversa.

Dekker, et al., (2013) sugerem a mudança de mentalidade no planejamento empresarial como importante fator gerador de demandas reversas, uma vez que foi constatado o aumento da importância do fluxo reverso em detrimento ao pensamento de que são apenas produtos seguindo o fluxo contrário ao fluxo logístico convencional.

O crescimento destacado da logística e fluxos reversos são justificados pelo aumento de duas principais forças no segmento empresaria, a primeira delas é a preocupação com meio ambiente, seja ele influenciado por novos pensamentos ligados a sustentabilidade ou por novas leis propostas pelo legislativo, e a influência nos custos da empresa através de ganhos extras gerados pelos produtos retornados (Meade, et al., 2007).

Assim, a logística reversa ganha importância como a área de planejamento, operação e controle de fluxos e informações logísticas no sentido de retorno de bens no canal de distribuição reverso para reutilização do produto ou reaproveitamento de seus componentes. Enquanto a logística tradicional lida com o fluxo de produtos a jusante na cadeia, a logística reversa trata do fluxo a montante, isto é, após o seu consumo o fluxo de material se direciona para o início do processo produtivo (Leite, 2002; Pires, 2004).

No óleo de cozinha a prática é similar, o retorno leva o produto usado constituir-se como matéria prima parte do processo de outros subprodutos, como biodiesel, tinta, sabão e detergentes, por exemplo (Pitta Junior, et al., 2009).

Melo e outros (2009) destaca a existência de três principais fatores que motivam a utilização da logística para auxiliar o gerenciamento da cadeia de suprimentos no fluxo reverso dos produtos e informações, são eles os aspectos econômicos, as leis governamentais e o mercado.

No primeiro deles, as questões econômicas se tratam do ganho financeiro obtido com o retorno dos produtos. Especificamente, a respeito do fluxo de retorno do óleo de cozinha usado já foram apresentados subprodutos que podem contem como uma de suas matérias-primas esse resíduo.

O segundo aspecto é referente ao ponto de vista da legislação, quando alguma lei aponta a necessidade ou obrigatoriedade do recolhimento do produto, atribuindo obrigações para um ou mais atores da cadeia de suprimentos daquele bem. De forma direcionada, o Brasil através da Lei 12.305 de 2010 (Brasil, 2010) instituiu a PNRS.

Caso particular apresentado pelo autor, quando ocorre a existência de legislação municipal, a fiscalização ocorreria de maneira apropriada, fazendo com que os responsáveis cumpram o estabelecido por Lei. 

logística reversa com níveis de capacidade. Brazilian Journal of Production Engineering, 6(7), 1-22.

Em Vitória - ES, o Projeto de Lei 308 de 2014 (Vitória, 2014a) foi aprovado por seus pares e determina a obrigatoriedade de estabelecimentos que praticam a venda do óleo de cozinha manter em local visível um recipiente especial para o seu descarte.

Por fim, o mercado se relaciona com a questão a partir da diferenciação da empresa no ponto de vista do cliente, ao se criar uma imagem ambiental consciente pela população.

Apesar da população não estar ciente dos malefícios causados pela contaminação da água pelo óleo, um litro de óleo pode poluir 20 mil litros de água (Brasil, 2014), a empresa que promover esse retorno ou participar de alguma forma nesse ciclo reverso pode ter sua imagem solidificada no ponto de vista ambiental.

\section{O PROBLEMA DA POSTERGAÇÃO DE TEMPO NA REDE LOGÍSTICA REVERSA DO ÓLEO DE COZINHA}

A partir da coleta deste óleo usado, o fluxo deste material se direciona para os centros de tratamento (CT). Um CT tem como objetivo oferecer um tratamento prévio ao óleo usado a fim de eliminar impurezas antes de encaminhá-lo para uma indústria de beneficiamento (Leite, 2009).

A instalação de destino deste óleo coletado definido nesta pesquisa é uma empresa de beneficiamento de resíduo (EBR). Essa empresa vai proporcionar ao óleo usado um fim adequado, de forma a ser reutilizado na indústria ou pela população para outros fins como, por exemplo, sabão, biodiesel ou tinta (Gonçalves, 2015).

Embora a rede contenha estes participantes como atores principais, a caracterização deste estudo indica a utilização de um estoque na cadeia para que seja um estudo de postergação de tempo.

Dessa forma, como participante fundamental deste estudo aparece a utilização de estoques e por se tratar de postergação de tempo, este estudo de centralização de fluxos para um estoque possui limitações de tipo de instalações para que ocorra a postergação de tempo.

Em um estudo de postergação de tempo, o estoque deverá ser localizado em um nível da cadeia de suprimentos que não seja o último estágio por, nesta situação, se tratar de um estudo do princípio da especulação.

Assim, como neste estudo tem-se três estágios, teremos a opção de utilizar o estoque no nível local, ou seja, em um dos bairros geradores da demanda de retorno, ou em um segundo nível, em uma instalação onde ocorrer um pré-tratamento antes de enviar para a EBR.

Dessa forma, na primeira opção, os bairros geradores de demanda poderão enviar os resíduos para um destes bairros, concentrando o fluxo para um ponto específico e, a partir deste ponto, direcionar para o nó seguinte. Se tratando deste tipo de configuração, o óleo recebido no estoque será o óleo usado, isto é, um óleo sem tratamento, pois ainda não passou pelo processo de eliminação de impurezas que ocorre no CT.

A outra opção é a localização do estoque em algum dos bairros, recebendo o fluxo diretamente do segundo nível, um CT. Como o óleo já teve passagem pelo CT, neste caso se aborda um óleo

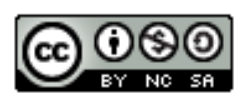



logística reversa com níveis de capacidade. Brazilian Journal of Production Engineering, 6(7), 1-22.

tratado, sendo assim, este estoque será chamado de estoque de óleo tratado para diferenciar o caso anterior, o estoque de óleo usado

\subsection{MODELO MATEMÁtico}

A Figura 1 apresenta um esquema simplificado do funcionamento da rede logística considerada neste projeto. Pela figura verifica-se a inter-relação dos integrantes da rede, bem como os fluxos diretos e possíveis casos de abertura de um estoque entre dois tipos de instalações.

Destaca-se também, o fluxo entre as instalações e, ainda, que um dos fluxos entre as instalações existirá caso a instalação seja aberta em um nível e a outro fluxo de transporte não, uma vez que a Postergação de Tempo, indica apenas a abertura de um estoque na rede logística.

Figura 1. (a) Esquematização simplificada de possíveis locais para postergação na rede logística e (b) Rede logística com postergação de tempo

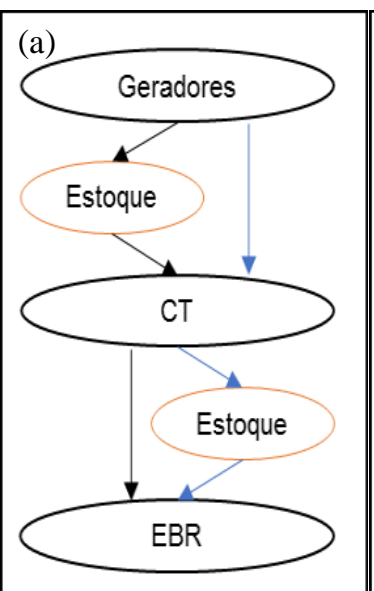

(b)

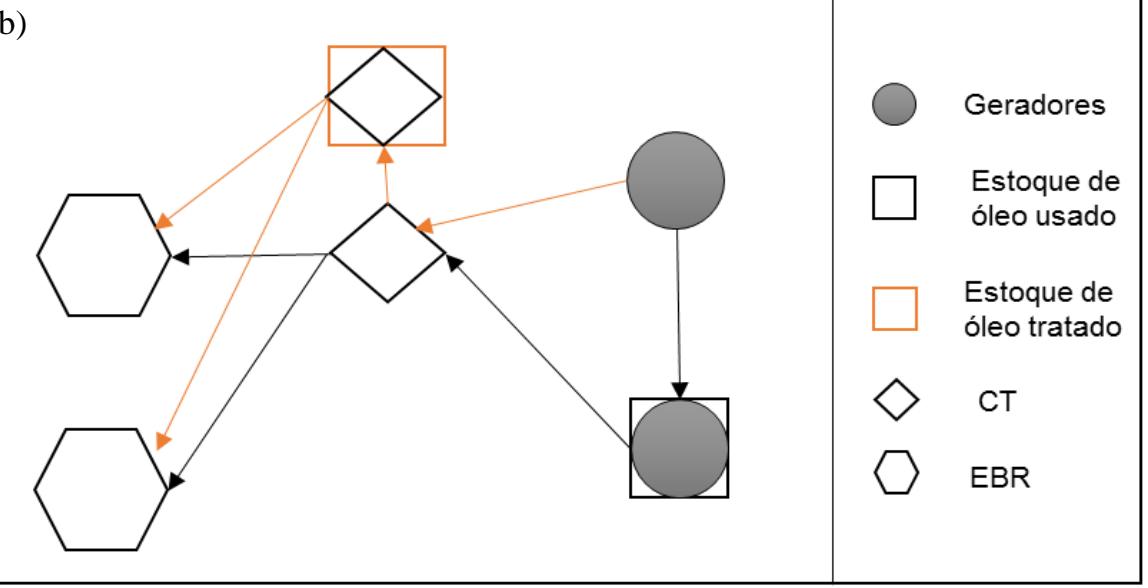

O modelo foi desenvolvido com base na rede logística estudada, dos quais a estrutura de fluxo e utilização da postergação de tempo no projeto de rede logística são oriundos de Servare Junior, et al., (2018), onde os autores utilizaram a modelagem matemática para projeto de rede logística com postergação de tempo para o fluxo direto. As diferenças principais é a inclusão de níveis de capacidade ao modelo, a adaptação para descontos em caso de abertura de qualquer estoque e a adaptação para o modelo se tornar um modelo Programação Linear Inteira Mista (PLIM).

A seguir estão descritos os conjuntos, parâmetros e variáveis do modelo matemático proposto.

Conjuntos

$H \quad$ Conjunto de localização fixa dos bairros geradores de demanda $h \in H$

I Conjunto de potenciais localizações de um estoque de óleo usado $i \in I$ em um bairro gerador de

demanda

$J \quad$ Conjunto de potenciais localizações de um centro de tratamento $j \in J$

$K \quad$ Conjunto de potenciais localizações de um estoque de óleo tratado $k \in K$ em um centro de tratamento

$L \quad$ Conjunto de localização fixa das empresas de beneficiamento de resíduos $l \in L$

$E \quad$ Conjunto de bairros que podem possuir um centro de tratamento e estoque ao mesmo tempo $e \in$

$E, e \subset J, e \subset K$

$N \quad$ Conjunto dos níveis de capacidade disponíveis para instalação $n \in N$

Parâmetros

$F w_{i} \quad$ Custos fixos de abertura de um estoque de óleo usado em $i$

$F x_{j}^{n} \quad$ Custos fixos de abertura de um centro de tratamento em $j$ na faixa de capacidade $n$

$F y_{k} \quad$ Custos fixos de abertura de um estoque de óleo tratado em $k$ 
Citação (APA): Servare Junior, M. W. J., \& Cardoso, P. A. (2020). Modelo matemático para postergação de tempo no projeto de rede logística reversa com níveis de capacidade. Brazilian Journal of Production Engineering, 6(7), 1-22.

$f_{e} \quad$ Redução de custos fixos associados com a abertura de um centro de tratamento e um estoque em $e$

$C p_{h i} \quad$ Custo de transporte por litro de óleo usado do bairro gerador de demanda $h$ para o estoque de óleo usado em $i$

$C q_{h j} \quad$ Custo de transporte por litro de óleo usado do bairro gerador de demanda $h$ para o centro de tratamento em $j$

$\mathrm{Cr}_{i j} \quad$ Custo de transporte por litro de óleo usado do estoque de óleo usado em $i$ para o centro de tratamento em $j$

$C s_{j k} \quad$ Custo de transporte por litro de óleo tratado do centro de tratamento $j$ para o estoque de óleo tratado em $k$

$C t_{j l} \quad$ Custo de transporte por litro de óleo tratado do centro de tratamento em $j$ para a empresa beneficiadora de resíduo $l$

$C u_{k l} \quad$ Custo de transporte por litro de óleo tratado do estoque de óleo tratado em $k$ para o varejo $l$

$d_{h} \quad$ Quantidade demandada de óleo usado em $h$

$x_{h} \quad$ Percentual de óleo usado recolhido em $h$

$p \quad$ Percentual de perda no processo de tratamento

Nmax Quantidade máxima de centro de tratamentos abertos

caw $_{i} \quad$ Capacidade do estoque de óleo usado em $i$

$\operatorname{cax}_{j}^{n} \quad$ Capacidade do centro de tratamento em $j$ na faixa de capacidade $n$

cay $_{k} \quad$ Capacidade de óleo tratado no estoque em $k$

$\mathrm{cal}_{l} \quad$ Capacidade da empresa beneficiadora de resíduos $l$

Variáveis

$W_{i} \quad=1$ se um estoque de óleo usado é aberto em $i ; 0$ caso contrário

$X_{j}^{n} \quad=1$ se um centro de tratamento é aberto em $j$ na faixa de capacidade $n ; 0$ caso contrário

$Y_{k} \quad=1$ se um estoque de óleo tratado é aberto em $k$ no $2^{\circ}$ nível da rede; 0 caso contrário

$Z_{e} \quad=1$ se um centro de tratamento e um estoque de óleo tratado forem abertos simultaneamente em $e, 0$ caso contrário

$P_{h i} \quad$ Quantidade transportada de óleo usado em $h$ para o estoque de óleo usado $i$

$Q_{h j} \quad$ Quantidade transportada de óleo usado em $h$ para o centro de tratamento em $j$

$R_{i j} \quad$ Quantidade transportada de óleo usado do estoque de óleo usado em $i$ para o centro de tratamento em $j$

$S_{j k} \quad$ Quantidade transportada de óleo tratado do centro de tratamento em $j$ para o estoque de óleo tratado em $k$

$T_{j l} \quad$ Quantidade transportada de óleo tratado do centro de tratamento em $j$ para a empresa beneficiadora de resíduo $l$

$U_{k l} \quad$ Quantidade transportada de óleo tratado do estoque de óleo tratado em $k$ para a empresa beneficiadora de resíduo $l$

De acordo com a notação definida, a seguir é apresentado o modelo matemático proposto baseado na proposta de Servare Junior et al. (2018).

$$
\begin{aligned}
\operatorname{Min} \sum_{i \in I} F w_{i} W_{i} & +\sum_{j \in J} F x_{j}^{n} X_{j}^{n}+\sum_{k \in K} F y_{k} Y_{k}-\sum_{e \in E} f_{e} Z_{e}+\sum_{h \in H} \sum_{i \in I} C p_{h i} P_{h i}+\sum_{h \in H} \sum_{j \in J} C q_{h j} Q_{h j} \\
& +\sum_{i \in I} \sum_{j \in J} C r_{i j} R_{i j}+\sum_{j \in J} \sum_{k \in K} C s_{j k} S_{j k}+\sum_{j \in J} \sum_{l \in L} C t_{j l} T_{j l}+\sum_{k \in K} \sum_{l \in L} C u_{k l} U_{k l}
\end{aligned}
$$

Sujeito a:

$$
\begin{aligned}
& \sum_{i \in I} P_{h i}+\sum_{j \in J} Q_{h j}=x_{h} \cdot d_{h} \forall h \in H \\
& \sum_{h \in H} P_{h i}=\sum_{j \in J} R_{i j} \forall i \in I \\
& (1-p) \cdot\left(\sum_{h \in H} Q_{h j}+\sum_{i \in I} R_{i j}\right)=\sum_{k \in K} S_{j k}+\sum_{l \in L} T_{j l} \forall j \in J
\end{aligned}
$$




$$
\begin{aligned}
& \sum_{j \in J} S_{j k}=\sum_{l \in L} U_{k l} \forall k \in K \\
& \sum_{h \in H} P_{h i} \leq \operatorname{caw}_{i} W_{i} \quad \forall i \in I \\
& \sum_{h \in H}^{h \in H} Q_{h j}+\sum_{i \in I} R_{i j} \leq \sum_{n \in N} \operatorname{cax}_{j}^{n} X_{j}^{n} \quad \forall j \in J \\
& \sum S_{j k} \leq \operatorname{cay}_{k} Y_{k} \quad \forall k \in K \\
& \sum_{j \in J}^{j \in J} T_{j l}+\sum_{k \in K} U_{k l} \leq \operatorname{cal}_{l} \quad \forall l \in L \\
& \sum_{i \in I} W_{i}+\sum_{k \in K} Y_{k}=1 \\
& \sum X_{j}^{n} \leq 1 \quad \forall j \in J \\
& \sum_{i \in I}^{n \in N} \sum_{k \in K} X_{j}^{n} \leq N \max \quad \forall j \in J \\
& \sum_{j \in J} Q_{h j} \leq\left(1-\sum_{i \in I} W_{i}\right) \cdot x_{h} \cdot d_{h} \quad \forall h \in H \\
& \sum_{j \in J} T_{j l} \leq\left(1-\sum_{k \in K} Y_{k}\right) \cdot \operatorname{cal}_{l} \quad \forall l \in L \\
& 2 * Z_{e} \leq W_{e}+\sum_{n \in N} X_{e}^{n}+Y_{e} \quad \forall e \in E \\
& P_{h i}, Q_{h j}, R_{i j}, S_{j k}, T_{j l}, U_{k l} \geq 0 \quad \forall i \in I, j \in J, k \in K, h \in H, l \in L \\
& W_{i}, X_{j}, Y_{k}, Z_{e} \in\{0,1\} \forall i \in I, j \in J, k \in K, e \in E
\end{aligned}
$$

A função objetivo (1) minimiza o custo total, abrangendo os custos fixos, como os custos de abertura, além dos custos variáveis (custos de transportes) que estão relacionados com a quantidade de mercadoria transportada em cada trecho.

O conjunto de restrições (2) assegura que a demanda de óleo usada disponibilizada em cada bairro é recolhida. Já os conjuntos (3), (4) e (5) são restrições relativas aos fluxos de entrada e saída dos estoques de óleo usado, centros de tratamento e estoques de óleo tratado, respectivamente.

As restrições (6) a (9) limitam que as quantidades enviadas às instalações ou enviadas a partir destas sejam menores que as suas capacidades, caso estas forem abertas. A restrição (10) garante que haverá apenas a utilização de um estoque, seja ele de óleo usado ou óleo tratado, condição que indica a postergação de tempo como fator para este estudo.

O conjunto de restrições (11) indica que será aberto no máximo um centro de tratamento por bairro e a restrição (12) limita a quantidade de centros de tratamento abertas na rede logística.

As restrições (13) asseguram que caso um estoque de óleo usado seja aberto, todos os produtos passarão por este estoque antes de ir para centro de tratamento. Por sua vez, em (14) é garantido que caso um estoque de óleo tratado seja aberto, todos os produtos oriundos do centro de 

logística reversa com níveis de capacidade. Brazilian Journal of Production Engineering, 6(7), 1-22.

tratamento passarão por este estoque antes de serem direcionados à empresa beneficiadora de resíduos.

As restrições (15) indicam que o valor de desconto na função objetivo vai acontecer somente com abertura de um estoque e um centro de tratamento no mesmo bairro.

E, por fim, as restrições (16) e (17) referem-se ao domínio das variáveis.

\subsection{ElaboraÇÃo dOS CENÁRIOS}

Os procedimentos adotados para a elaboração de cenários constituem alterações em parâmetros de entrada do modelo, visando uma maior abrangência em relação a possibilidades de localização, capacidades, Horizonte de Planejamento (HP) e custos a partir da utilização da modelagem matemática desenvolvida.

Cada caso estudado agrupa informações que alteram a dinâmica da resposta e proporcionam alteração no valor da função objetivo do modelo. Os cenários estão agrupados de acordo com o limite de CT's abertos na cadeia.

A divisão político-administrativa de Vitória foi importante para essa análise, uma vez que a cidade é dividida em regiões administrativas. Além deste tipo de divisão, também foi considerada nesta abordagem a divisão do município de Vitória considerando o contexto geográfico.

Da mesma forma, considerando uma taxa de perda no processo de tratamento essa margem foi estipulada para que contemplasse maior precisão e mais conjuntos de opções neste estudo. Outro importante fator de tratamento de dados para elaboração de cenários foi o estudo quanto ao horizonte de planejamento, isto é, a vida útil projetada para o projeto de cadeia de suprimentos estudado. Este fator se torna essencial na análise quando é projetado um consumo durante este período e, este, influência de forma direta nos custos envolvidos.

Na Tabela 1 são apresentados de forma detalhada os parâmetros utilizados para a variação e estudos dos cenários. Dentre eles estão os já descritos nesta seção e outros que foram considerados no desenvolvimento desta pesquisa e que se tornam importantes à medida que podem causar impacto nas escolhas do modelo.

Tabela 1. Cenários de estudo avaliados

\begin{tabular}{|c|c|c|c|c|c|c|c|}
\hline \multirow[b]{2}{*}{ Grupo } & \multirow[b]{2}{*}{ Cenário } & \multicolumn{2}{|c|}{ Custos } & \multirow[b]{2}{*}{$\begin{array}{l}\text { Horizonte de } \\
\text { Planejamento }\end{array}$} & \multirow[b]{2}{*}{$\begin{array}{l}\text { Perda de } \\
\text { Produção }\end{array}$} & \multirow{2}{*}{$\begin{array}{c}\text { Limite de } \\
\text { CT's } \\
\text { abertos } \\
\end{array}$} & \multirow{2}{*}{$\begin{array}{l}\text { Níveis de } \\
\text { capacidade }\end{array}$} \\
\hline & & Fixos & Variáveis & & & & \\
\hline \multirow{4}{*}{1} & 1.1 & $\mathrm{X}$ & $\mathrm{X}$ & 5 anos & $10 \%$ & 8 & 4 \\
\hline & 1.2 & & $\mathrm{x}$ & 5 anos & $10 \%$ & 8 & 4 \\
\hline & 1.3 & $\mathrm{x}$ & $\mathrm{x}$ & 15 anos & $10 \%$ & 8 & 4 \\
\hline & 1.4 & & $\mathrm{x}$ & 15 anos & $10 \%$ & 8 & 4 \\
\hline \multirow{4}{*}{2} & 2.1 & $\mathrm{x}$ & $\mathrm{x}$ & 5 anos & $25 \%$ & 8 & 4 \\
\hline & 2.2 & & $\mathrm{x}$ & 5 anos & $25 \%$ & 8 & 4 \\
\hline & 2.3 & $\mathrm{x}$ & $\mathrm{x}$ & 15 anos & $25 \%$ & 8 & 4 \\
\hline & 2.4 & & $\mathrm{x}$ & 15 anos & $25 \%$ & 8 & 4 \\
\hline \multirow{4}{*}{3} & 3.1 & $\mathrm{x}$ & $\mathrm{x}$ & 5 anos & $10 \%$ & 2 & 4 \\
\hline & 3.2 & & $\mathrm{x}$ & 5 anos & $10 \%$ & 2 & 4 \\
\hline & 3.3 & $\mathrm{x}$ & $\mathrm{x}$ & 15 anos & $10 \%$ & 2 & 4 \\
\hline & 3.4 & & $\mathrm{x}$ & 15 anos & $10 \%$ & 2 & 4 \\
\hline 4 & 4.1 & $\mathrm{x}$ & $\mathrm{x}$ & 5 anos & $25 \%$ & 2 & 4 \\
\hline
\end{tabular}


Citação (APA): Servare Junior, M. W. J., \& Cardoso, P. A. (2020). Modelo matemático para postergação de tempo no projeto de rede logística reversa com níveis de capacidade. Brazilian Journal of Production Engineering, 6(7), 1-22.

\begin{tabular}{|c|c|c|c|c|c|c|c|}
\hline & 4.2 & & $\mathrm{x}$ & 5 anos & $25 \%$ & 2 & 4 \\
\hline & 4.3 & $\mathrm{X}$ & $\mathrm{x}$ & 15 anos & $25 \%$ & 2 & 4 \\
\hline & 4.4 & & $\mathrm{x}$ & 15 anos & $25 \%$ & 2 & 4 \\
\hline \multirow{4}{*}{5} & 5.1 & $\mathrm{x}$ & $\mathrm{x}$ & 5 anos & $10 \%$ & 1 & 1 \\
\hline & 5.2 & & $\mathrm{x}$ & 5 anos & $10 \%$ & 1 & 1 \\
\hline & 5.3 & $\mathrm{x}$ & $\mathrm{x}$ & 15 anos & $10 \%$ & 1 & 1 \\
\hline & 5.4 & & $\mathrm{x}$ & 15 anos & $10 \%$ & 1 & 1 \\
\hline \multirow{4}{*}{6} & 6.1 & $\mathrm{x}$ & $\mathrm{x}$ & 5 anos & $25 \%$ & 1 & 1 \\
\hline & 6.2 & & $\mathrm{x}$ & 5 anos & $25 \%$ & 1 & 1 \\
\hline & 6.3 & $\mathrm{x}$ & $\mathrm{x}$ & 15 anos & $25 \%$ & 1 & 1 \\
\hline & 6.4 & & $\mathrm{x}$ & 15 anos & $25 \%$ & 1 & 1 \\
\hline
\end{tabular}

A primeira forma de separação entre os cenários foi a limitação de quantidade de CT’s que podem ser abertas. Os Grupos 1 e 2 tiveram como fator limite a divisão político-administrativa de Vitória que conta com a divisão do território em 8 regiões administrativas, conforme apresentado pelo IBGE (2010) citado pela Prefeitura de Vitória (Vitória, 2011). Esta divisão pode ser observada na Lei $\mathrm{n}^{\circ} 8.611$ de 2014 (Vitória, 2014b) que contém os limites administrativos. Embora os limites administrativos tenham sido alterados para 9 regiões, para efeito de observação do procedimento deste estudo as regiões administrativas de Jardim da Penha e Goiabeiras são consideradas uma, conforme limites anteriores a esta Lei.

Posteriormente, os Grupos 3 e 4 foram condicionados às caraterísticas geográficas que o território de Vitória apresenta. Assim, foram limitadas em no máximo 2 possibilidades de abertura, uma na ilha de Vitória e outra dentro dos limites continentais do município.

Por fim, os Grupos 5 e 6 apresentam a restrição de $1 \mathrm{CT}$ aberto em todo limite municipal.

Por sua vez, os custos foram divididos em duas opções, a primeira contabiliza tanto o Custo Variável quanto o Custo Fixo como forma de apresentar uma solução com todos os fatores envolvidos. A segunda opção se trata de conhecer e identificar o comportamento do fator transporte e sua influência na distribuição do óleo na cadeia.

Considerando a perda que acontece no processo de tratamento pra retirada de impurezas, foram usados os valores de $10 \%$ e $25 \%$ para que pudessem, também, demonstrar sua importância na escolha dos estoques, uma vez que quanto maior for a perda o custo de instalar um estoque de óleo tratado será menor do que um estoque de óleo usado, devido à sua capacidade de operar em uma faixa inferior ocasionada pela perda.

Os níveis de capacidade de um CT permaneceram fixos durante todo o desenvolvimento de cenários para que a combinação entre os 4 níveis propostos $(25 \%, 50 \%, 75 \%$ ou $100 \%$ da demanda) pudesse ser usada em sua totalidade (Grupos 5 e 6) ou em combinação de acordo com a necessidade (Grupos 1 a 4 ).

A última característica analisada no desenvolvimento dos cenários foi o tempo considerado para cálculo das demandas e planejamento da rede. Os valores 5 e 15 anos foram escolhidos por abranger o planejamento em médio e longo prazo e propor soluções para um período de tempo que incentive a instalação da rede. 

logística reversa com níveis de capacidade. Brazilian Journal of Production Engineering, 6(7), 1-22.

\subsection{OBTENÇÃO DOS DADOS}

Por sua vez, os valores utilizados como parâmetros no modelo matemático para aplicação no estudo de caso da cadeia logística reversa do óleo de cozinha no município de Vitória, bem como a origem de cada um destes são apresentados nesta seção.

A produção de óleo de cozinha usado em Vitória foi definida a partir da pesquisa de Madalozo (2008) que estimou o consumo mensal de óleo de Ponta Grossa, Paraná, com base na população e renda. Para tal, foram utilizadas informações advindas do IBGE e entrevistas domiciliares para que fosse cálculo da demanda regional de retorno do óleo de cozinha usado (Tabela 2).

Tabela 2. Consumo mensal de óleo baseado na renda

\begin{tabular}{cccccc}
\hline $\begin{array}{c}\text { Renda } \\
\text { (Salários mínimos/mês) }\end{array}$ & Até $\mathbf{1}$ & $\mathbf{1}$ até $\mathbf{3}$ & $\mathbf{3}$ até $\mathbf{5}$ & $\mathbf{5}$ até $\mathbf{1 0}$ & Acima de 10 \\
\hline $\begin{array}{c}\text { Consumo de óleo } \\
\text { (Litros/pessoa/mês) }\end{array}$ & 1,12 & 1,34 & 0,95 & 1,07 & 0,75 \\
$\begin{array}{c}\text { Geração de rejeito } \\
\text { (Litros/pessoa/mês) }\end{array}$ & 0,19 & 0,21 & 0,24 & 0,17 & 0,15 \\
Percentual de rejeito & $17 \%$ & $16 \%$ & $25 \%$ & $16 \%$ & $20 \%$ \\
\hline
\end{tabular}

Fonte: Adaptada de Madalozo (2008)

Para inserção destes valores na modelagem matemática foram contabilizados os dados da população de Vitória (Vitória, 2010a; IBGE, 2010) conforme as características apresentadas na Tabela 2.

Para elaboração das demandas, foi necessário contabilizar a população de acordo com cenários. Os dados apresentados pela Prefeitura de Vitória (2010a, apud IBGE, 2010) agrupam-se de acordo com faixa de renda para pessoas a partir de 10 anos de idade.

Dessa forma, foram contabilizados e agrupados os valores de forma pertinente ao apresentado na Tabela 2. , além da população excedente não contabilizada nos valores apresentados para renda, mas que foi contabilizada como população. Para isso, foram preenchidas as 4 últimas colunas, da população com renda de 1 a 3, 3 a 5, 5 a 10 e acima de 10 salários mínimos, e, então, a coluna de até 1 salário mínimo foi contabilizada a partir do total de população descontando as 4 colunas já preenchidas.

Como caráter ilustrativo um fragmento desta análise é apresentado na Tabela 3. , o procedimento usado no preenchimento dos campos da população do bairro Centro foi realizado da seguinte forma:

A população do bairro Centro foi contabilizada pelo Censo do IBGE (2010) como 9.838 habitantes. O Instituto, ainda, mensurou a população acima de 10 anos com renda de 1 a 3 salários mínimos como 2.516 pessoas, 1.304 pessoas recebendo de 3 a 5, outras 1.392 tem o rendimento enquadrado na faixa de 5 a 10 e 604 pessoas com o rendimento acima de 10 salários mínimos (Vitória, 2010a).

Tabela 3. Característica da população, renda e demanda do bairro Centro

\begin{tabular}{llllllcccc}
\hline \multirow{2}{*}{ Bairro } & \multirow{2}{*}{ População } & \multicolumn{4}{c}{ Renda em salários mínimos } & Consumo & \multicolumn{2}{c}{ Resíduo } \\
& & Até $\mathbf{1}$ & $\mathbf{1 ~ a ~ 3}$ & $\mathbf{3}$ a 5 & $\mathbf{5}$ a 10 & Mais de 10 & mensal & mensal \\
\hline Centro & 9.838 & 4.022 & 2.516 & 1.304 & 1.392 & 604 & 11.057 & 1.933 \\
\hline
\end{tabular}



logística reversa com níveis de capacidade. Brazilian Journal of Production Engineering, 6(7), 1-22.

Assim, para preenchimento da coluna “Até 1", de pessoas com rendimento até 1 salário mínimo foi contabilizado como o restante da população que não se enquadrava nos outros quesitos por algum motivo, seja qualquer a razão como, por exemplo, não possuir renda, ter ganhos de até 1 salário mínimo ou não possuir mais de 10 anos de idade.

Quanto às informações adicionais, o consumo foi calculado através da soma dos produtos entre a taxa de consumo por faixa de renda (vide Tabela 2) e a quantidade de pessoas naquela faixa de renda. Da mesma forma procedeu-se para o cálculo da quantidade de resíduo utilizando o valor de geração de rejeito para cada faixa de renda.

Por sua vez, os custos fixos (CF) são os custos que serão realizados em uma única oportunidade durante o processo de planejamento, não possuindo uma variação linear de acordo com a quantidade produzida. Na fase inicial de implantação a escolha de localização é um deles.

A alteração do volume de produção ou de capacidade de uma instalação afeta de forma discreta o valor do custo, ou seja, de acordo com uma faixa de capacidade ou de produção o custo permanecerá constante até o limite desta faixa, caracterizando assim o tratamento como custo fixo e não variável.

Os principais custos fixos envolvidos nesta pesquisa são o custo de abertura das instalações que serão discutidos nos tópicos a seguir.

Ponto primordial para este estudo, o custo de alocação de um estoque foi definido a partir de estimativas realizadas por Gonçalves (2015). No estudo, o autor não apresenta uma instalação específica para fazer o armazenamento na cadeia, embora planeje a capacidade das instalações de tratamento do óleo considerando a demanda mensal da rede.

Desta forma, no estudo de Gonçalves (2015) direciona a alocação de despesas de um estoque ao armazenamento no centro de tratamento. Realizando procedimento semelhante ao proposto naquela pesquisa, este projeto define como um estoque o acumulo de óleo na cadeia de suprimento, aguardando ser enviada ao próximo nível da cadeia.

Assim, para a formação de um estoque de óleo e, por consequência, a utilização da postergação de tempo, nesta pesquisa será necessária uma instalação ou uma adequação de instalação para que ocorra este armazenamento. No caso do óleo, a alternativa para que ocorra o armazenamento é a alocação de tanques que possam abrigar o produto até a movimentação ao nó a jusante na cadeia.

Por se tratar de um estudo de implantação de uma cadeia logística reversa, o interesse de autoridades municipais em realizar a coleta e a necessidade de um planejamento prévio de localização e capacidade de instalações, esta pesquisa considera que os custos necessários para implantação de estoques serão apenas relativos a adquirir os tanques para armazenamento do óleo.

Por sua vez, segue a consideração da utilização de uma área pública ou uma associação de coleta de resíduos para a manutenção do estoque. Essas alternativas eliminam os custos em adquirir um terreno para mobilizar um projeto de construção de instalação no local. 

logística reversa com níveis de capacidade. Brazilian Journal of Production Engineering, 6(7), 1-22.

Na Tabela 4 são apresentados valores para aquisição dos tanques, de forma que a capacidade de um estoque será definida com combinação da utilização destes equipamentos. Como exemplo, para um estoque de capacidade 75.000 litros serão utilizados dois tanques de 30.000 litros e um tanque de 20.000 litros.

Tabela 4. Custo de aquisição de tanques

\begin{tabular}{cc}
\hline Descrição & Custo \\
\hline Tanque $10.000 \mathrm{~L}$ & $\mathrm{R} \$ 4250,00$ \\
Tanque $20.000 \mathrm{~L}$ & $\mathrm{R} \$ 6820,00$ \\
Tanque $30.000 \mathrm{~L}$ & $\mathrm{R} \$ 9100,00$ \\
\hline
\end{tabular}

Fonte: Adaptado de Gonçalves (2015)

Por fim, para estimar os valores relacionados ao custo de transportes foi preciso estabelecer as distâncias entre os bairros envolvidos neste estudo. Os valores foram obtidos e a matriz custo de transporte foi preenchida com base em informações obtidas pelo Google Maps.

A ligação entre os bairros foi contabilizada considerando a localização fixa que é sugerida pelo aplicativo ao sinalizar como origem ou destino aquele bairro. Não houve nenhuma ligação que não pudesse ser realizada, sendo possível a conexão por diversos caminhos e escolhida a rota que indicasse o menor trecho a ser percorrido.

Para maior aproximação dos valores mensurados, é recomendada a movimentação entre os nós em horários com menor fluxo de veículos, para que sejam evitadas discrepâncias com a realidade. Outro importante fator considerado foi que o fluxo dentro de um mesmo bairro não tivesse um custo contabilizado, essa situação deve-se ao fato de o estudo não envolver a localização de pontos de coleta específico dentro de um bairro.

Ferri e outros (2015) mensuraram o custo de transporte do óleo em R $\$ 10,50$ / km/ton, para efeito de cálculos nesse estudo o valor utilizado foi de $\mathrm{R} \$ 0,0094$ / km/l, que constituiu em uma transformação de unidade de massa, tonelada, para a unidade de volume utilizada neste estudo. Embora unidades diferentes, o valor físico é o mesmo e foi obtida a partir do valor da densidade do óleo de cozinha. Este valor foi utilizado para a movimentação do produto em todos os estágios da cadeia de suprimentos reversa do óleo de cozinha. Foram selecionadas três empresas, Empresa 1 localizada em Cariacica, na região metropolitana de Vitória, Empresa 2 em Campos de Goytacazes, no norte do estado do Rio de Janeiro e Empresa 3 em Belo Horizonte.

\section{RESUltados E DiscuSsão}

Para solucionar a modelagem dos cenários foi utilizado um computador com processador Intel core i5, com 4 GB de memória RAM, operando sob o sistema operacional Microsoft Windows 10 Professional versão 64 bits para todos os 24 cenários propostos. O solver comercial CPLEX 12.6 (IBM, 2012) foi o software escolhido para resolver os cenários deste estudo, estabelecidos e apresentados na seção 3.2 do presente trabalho.

Os resultados desta implementação podem ser observados na Tabela 2, onde a coluna Grupo representa o agrupamento dos cenários, facilitando a observação dos impactos de cada alteração

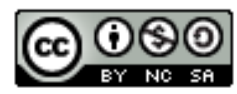



logística reversa com níveis de capacidade. Brazilian Journal of Production Engineering, 6(7), 1-22.

em uma visão superficial de casos similares com valores próximos. A coluna Cenário identifica o cenário daquele experimento, cada um com suas características específicas.

Tabela 2. Resultados dos cenários elaborados

\begin{tabular}{|c|c|c|c|c|c|c|}
\hline Cenário & $\begin{array}{r}\mathrm{C} \\
\text { (Fun }\end{array}$ & $\begin{array}{l}\text { Custo Total } \\
\text { ição Objetivo) }\end{array}$ & $\begin{array}{c}\text { Tempo de } \\
\text { processamento } \\
\text { (segundos) }\end{array}$ & $\begin{array}{l}\text { CT's } \\
\text { abertos }\end{array}$ & $\begin{array}{c}\text { Faixa de } \\
\text { capacidade }\end{array}$ & Tipo de estoque \\
\hline 1.1 & $\mathrm{R} \$$ & $4.731 .618,10$ & 88,79 & 1 & 4 & Óleo Usado \\
\hline 1.2 & $\mathrm{R} \$$ & $4.585 .511,94$ & 42,87 & 8 & 4 & Óleo Tratado \\
\hline 1.3 & $\mathrm{R} \$$ & $15.115 .092,21$ & 197,92 & 2 & $1 ; 2$ & Óleo Tratado \\
\hline 1.4 & $\mathrm{R} \$$ & $12.102 .180,35$ & 407,83 & 8 & 4 & Óleo Tratado \\
\hline 2.1 & $\mathrm{R} \$$ & $3.380 .399,25$ & 171,73 & 1 & 4 & Óleo Tratado \\
\hline 2.2 & $\mathrm{R} \$$ & $3.217 .984,12$ & 27,72 & 8 & 4 & Óleo Tratado \\
\hline 2.3 & $\mathrm{R} \$$ & $10.833 .996,25$ & 215,28 & 2 & $1 ; 2$ & Óleo Tratado \\
\hline 2.4 & $\mathrm{R} \$$ & $10.606 .010,36$ & 26,97 & 8 & $2 ; 4 ; 4 ; 4 ; 3 ; 1 ; 2 ; 2$ & Óleo Tratado \\
\hline 3.1 & $\mathrm{R} \$$ & $4.731 .618,10$ & 57,70 & 1 & 4 & Óleo Usado \\
\hline 3.2 & $\mathrm{R} \$$ & $4.620 .056,44$ & 30,95 & 2 & 4 & Óleo Tratado \\
\hline 3.3 & $\mathrm{R} \$$ & $15.138 .900,04$ & 71,52 & 1 & 4 & Óleo Tratado \\
\hline 3.4 & $\mathrm{R} \$$ & $15.006 .090,73$ & 97.91 & 2 & 4 & Óleo Tratado \\
\hline 4.1 & $\mathrm{R} \$$ & $3.380 .399,51$ & 227,02 & 1 & 4 & Óleo Tratado \\
\hline 4.2 & $\mathrm{R} \$$ & $3.259 .318,28$ & 116,57 & 2 & 4 & Óleo Tratado \\
\hline 4.3 & $\mathrm{R} \$$ & $10.889 .681,27$ & 267,19 & 1 & 4 & Óleo Tratado \\
\hline 4.4 & $\mathrm{R} \$$ & $10.737 .473,60$ & 511,32 & 2 & $2 ; 2$ & Óleo Tratado \\
\hline 5.1 & $\mathrm{R} \$$ & $4.731 .618,10$ & 34,17 & 1 & 1 & Óleo Usado \\
\hline 5.2 & $\mathrm{R} \$$ & $4.627 .414,26$ & 340,82 & 1 & 1 & Óleo Tratado \\
\hline 5.3 & $\mathrm{R} \$$ & $15.138 .900,04$ & 52,71 & 1 & 1 & Óleo Tratado \\
\hline 5.4 & $\mathrm{R} \$$ & $15.030 .018,41$ & 12,48 & 1 & 1 & Óleo Tratado \\
\hline 6.1 & $\mathrm{R} \$$ & $3.380 .399,25$ & 50,71 & 1 & 1 & Óleo Tratado \\
\hline 6.2 & $\mathrm{R} \$$ & $3.273 .413,17$ & 23,16 & 1 & 1 & Óleo Tratado \\
\hline 6.3 & $\mathrm{R} \$$ & $10.889 .681,27$ & 35,98 & 1 & 1 & Óleo Tratado \\
\hline 6.4 & $\mathrm{R} \$$ & $10.779 .086,27$ & 12,16 & 1 & 1 & Óleo Tratado \\
\hline
\end{tabular}

Já a coluna "Função Objetivo" representa o valor da solução em reais. No caso representado neste estudo é o gasto total para implementação desta configuração logística daquele cenário. A coluna tempo não tem impacto significante para a questão logística deste estudo, embora seja considerado um fator que requer cuidados no planejamento, uma vez que se fosse um valor demasiadamente grande poderia atrasar o desenvolvimento dos planos. Assim, a sua apresentação tem caráter informativo, para demonstrar quanto tempo durou a busca do computador pela solução ótima.

Por sua vez, o grupo de colunas CT’s irá apontar o número de CT’s abertos naquele cenário, seguido da sua localização e faixa de capacidade que o modelo indicou para que fosse aberta.

E, por fim, a coluna Estoques irá indicar o principal objetivo deste estudo, a adequação da rede daquele cenário para a utilização da postergação de tempo. Esta característica será formalizada com a sinalização por parte do modelo da localização onde ocorrerá a abertura de um estoque nesta cadeia de suprimentos reversa, além do tipo de estoque que deverá ser construído naquela localidade.

Do ponto de vista da implantação de estoques na rede logística, o Gráfico 1 discrimina a composição das localizações de estoque neste estudo de Postergação do Tempo na cadeia de 
- 17 -

Citação (APA): Servare Junior, M. W. J., \& Cardoso, P. A. (2020). Modelo matemático para postergação de tempo no projeto de rede logística reversa com níveis de capacidade. Brazilian Journal of Production Engineering, 6(7), 1-22.

suprimentos reversa. É de se notar a predominância da localização escolhida ser o bairro Parque Moscoso.

Gráfico 1. Frequência de escolha da localização do estoque em todos os cenários

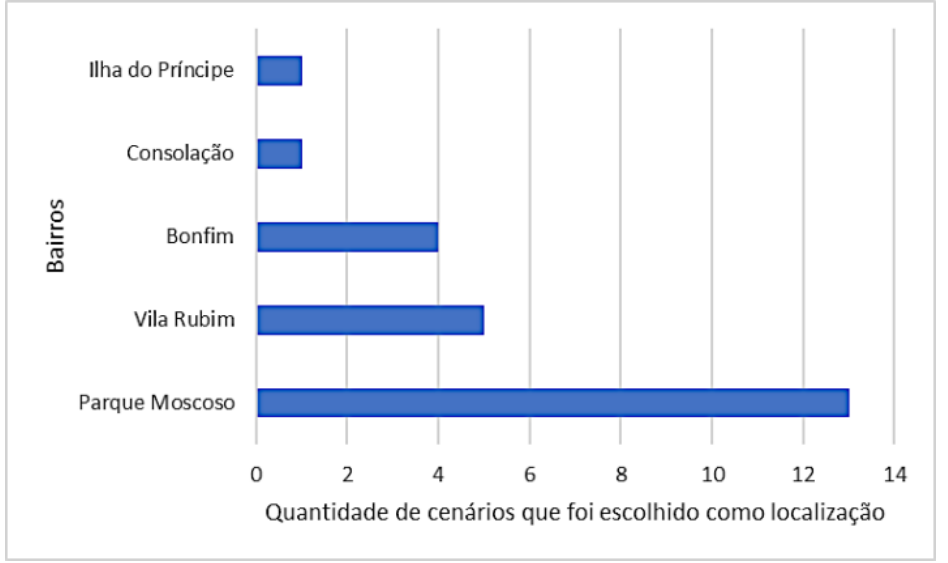

Da mesma maneira procede-se a caracterização quanto ao tipo de estoque que será implementado em cada cenário. Para a elaboração do Gráfico 2, as informações a respeito destas características foram contabilizadas e foi identificado que o estoque de óleo tratado é parte da solução da maioria dos cenários elaborados.

Gráfico 2. Quantidade de aparições de cada tipo de estoque em todos os cenários

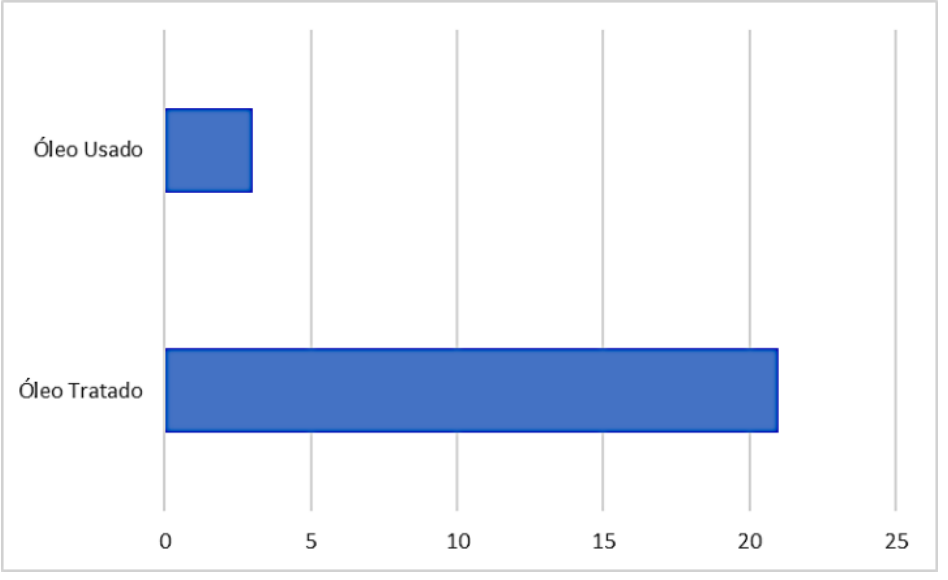

\subsection{Rede Logística Proposta}

Para que se tenha um maior dimensionamento desta rede e sabendo que uma rede logística é projetada para trabalhar em um horizonte de longo prazo, algumas considerações devem ser observadas para propor qual cenário deverá servir como base para a proposta de um projeto de rede logística com postergação de tempo para a cadeia de suprimentos reversa do óleo de cozinha.

O primeiro aspecto a ser observado é o horizonte de planejamento, uma vez que o projeto deve ser realizado com a perspectiva de HP longo. Neste estudo, foram elaborados cenários com duas opções de tempo para HP, a alternativa que contempla um maior período é o HP de 15 anos.

O segundo aspecto a ser levantado para consideração dos cenários é relativo à perda no processo de tratamento. Como este projeto de rede logística se sustenta na minimização de custos, o

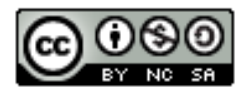



logística reversa com níveis de capacidade. Brazilian Journal of Production Engineering, 6(7), 1-22.

retorno obtido com a prática da logística reversa do óleo de cozinha não deverá ser apenas uma atividade custosa, como também uma atividade que gere retorno para os participantes.

Este retorno se torna fundamental à medida que os custos de funcionamento das instalações, como funcionários, custos com manutenção e gastos mensais e eventuais, entre outros, deverá ser utilizado para cobertura dessas despesas ou outros que, porventura, surjam.

Dessa forma, uma rede logística que contemple de forma mais abrangente essa situação deverá ter uma menor quantidade de perda no processo de tratamento. Como neste estudo foram consideradas duas taxas médias de perda, de $10 \%$ e $25 \%$, a que se enquadra nesse padrão é a de menor valor.

Por fim, para seleção dos cenários deverá ser considerado o custo envolvido e, assim, os cenários que não contemplem a inclusão dos custos fixos são descartados desta análise (Tabela $3)$.

Tabela 3. Cenários que atendem os critérios para formulação das propostas

\begin{tabular}{lrcccc}
\hline Cenário & FO & $\begin{array}{c}\text { Tempo } \\
\text { (segundos) }\end{array}$ & $\begin{array}{c}\text { CT's } \\
\text { abertos }\end{array}$ & $\begin{array}{c}\text { Faixa de } \\
\text { capacidade }\end{array}$ & $\begin{array}{c}\text { Tipo de } \\
\text { estoque }\end{array}$ \\
\hline 1.3 & $15.115 .092,21$ & 197,92 & 2 & $1 ; 2$ & Óleo Tratado \\
3.3 & $15.138 .900,04$ & 71,52 & 1 & 4 & Óleo Tratado \\
5.3 & $15.138 .900,04$ & 52,71 & 1 & 1 & Óleo Tratado \\
\hline
\end{tabular}

Diante das soluções que se enquadram nestes quesitos, o cenário 1.3 apresenta um menor valor da FO, sendo assim em um estudo de minimização de custos a escolha indicada. Com isso, o cenário 1.3 apresenta a configuração logística proposta por este estudo. Nesta opção serão abertos dois CT's e um estoque de óleo tratado, o primeiro CT é uma instalação híbrida, com funcionamento paralelo do estoque no mesmo local (Figura 2).

Figura 2. Resultado do cenário 1.3.

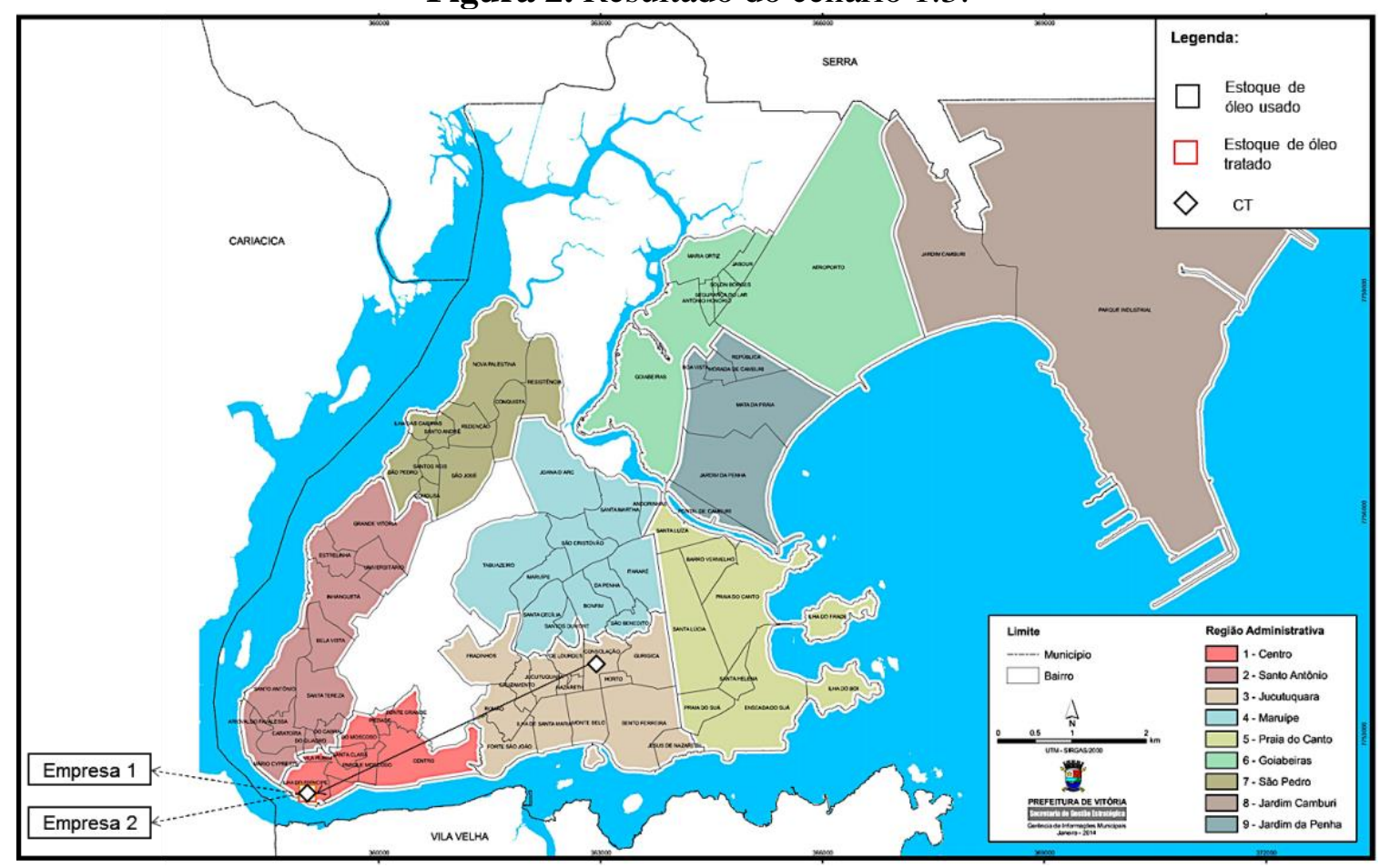

Fonte: Adaptado de Vitória (2014b)

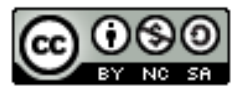



logística reversa com níveis de capacidade. Brazilian Journal of Production Engineering, 6(7), 1-22.

Embora as definições das faixas de capacidade indicassem a Faixa 1 recebendo $25 \%$ da demanda e a Faixa 2 com capacidade de $50 \%$ do total da demanda, a combinação dos tanques excedeu esses valores pré-estabelecidos. Embora ocorra essa situação, os dois CT's são suficientes, com estas faixas de capacidade para receber toda a demanda oriunda de cada bairro.

Uma vez enviadas as demandas dos bairros aos CT's abertos na cadeia, esse fluxo de óleo usado passará pelo processo de tratamento e, posteriormente, será enviado ao estoque de óleo tratado.

Assim, é constado que o modelo proposto é capaz de realizar o planejamento da logística reversa do óleo de cozinha no município de Vitória, no estado do Espírito Santo. O modelo foi capaz de minimizar os custos de abertura de instalações e custos de transporte.

Por fim, o estudo apresentou um novo modelo para projetos de cadeia de suprimentos com a postergação de tempo e, dentre os casos observados na literatura, foi o primeiro trabalho a implementar este tipo de estudo em uma cadeia de abastecimento reversa e indicado para ser usado em casos similares, tanto da logística tradicional quanto da logística reversa.

\section{Conclusões}

O modelo matemático demonstrou ser capaz de realizar o planejamento logístico reverso de óleo de cozinha usado e estruturar toda a cadeia de suprimentos proposta neste estudo, contendo as quantidades, origem e destinos das etapas relacionados ao transporte de óleo e, ainda, identificar abertura de instalações e suas localizações ótimas, faixas de capacidades dos CT's e tipos de estoques.

Este estudo, ainda, projetou fluxos de transportes entre as facilidades de acordo com as demandas locais e capacidades de cada instalação. Para isso, os custos de transportes foram mensurados a partir de levantamentos geográficos sobre a distâncias entre os bairros associadas ao custo unitário para o transporte do óleo de cozinha entre as instalações.

No levantamento bibliográfico foram obtidas informações e técnicas necessárias para a realização do estudo de caso, considerando aspectos importantes para as duas análises principais deste trabalho. A primeira é a postergação de tempo para projetar a cadeia de suprimentos e localizar um estoque em um nível diferente do último nó da rede e, posteriormente, a logística reversa para levantar pontos e conceitos importantes para incrementar no modelo.

Com isso, um modelo matemático foi desenvolvido para aplicação da postergação de tempo no projeto da cadeia de suprimentos reversa do óleo de cozinha usado e foi submetido aos dados a respeito de custos, demandas e capacidades, entre outros, obtidos com o levantamento.

O solver CPLEX 12.6 (IBM, 2012) se mostrou eficiente para resolver todos os cenários com um esforço computacional baixo, este medido em relação ao tempo de processamento da solução.

Com isso, motivado pela possibilidade de redução de custos e com o incentivo para o aumento da capacidade foram criados e analisados cenários para que a proposta com uma capacidade suficiente para atendimento integral da demanda. As soluções obtidas apresentam o custo minimizado. 
Citação (APA): Servare Junior, M. W. J., \& Cardoso, P. A. (2020). Modelo matemático para postergação de tempo no projeto de rede logística reversa com níveis de capacidade. Brazilian Journal of Production Engineering, 6(7), 1-22.

Os resultados apresentados com a implementação do modelo resultam em alternativas para a tomada de decisão de gestores de empresas que participam da cadeia reversa do óleo de cozinha e, ainda, de autoridades públicas que competem essas decisões de estabelecer diretrizes para a projeto de rede logística deste estudo de caso.

Assim, como sugestão para trabalhos futuros será implementar essa modelagem matemática para em redes logísticas reversas com cobertura ainda maior como, por exemplo, a nível estadual ou nacional, para validar a utilização dessa ferramenta em problemas ainda maiores, ainda, utilizar outras técnicas de solução para identificar o desempenho de outras ferramentas para resolver este problema e realizar uma atualização no estudo com base em dados populacionais atualizados quando estes forem divulgados.

\section{Agradecimentos}

O presente trabalho foi realizado com apoio da Coordenação de Aperfeiçoamento de Pessoal de Nível Superior - Brasil (CAPES) - Código de Financiamento 001.

\section{REFERÊNCIAS}

Alderson, W. (1950) Marketing efficiency and the principle of postponement. Cost and Profit Outlook.

Aviv, Y., \& A. Federgruen (2001). Design for postponement: A comprehensive characterization of its benefits under unknown demand distributions. Operations Research, 49(4), 578-598.

Brasil (2010). Lei no 12.305, de 02 de agosto de 2010. Institui a Política Nacional de Resíduos Sólidos; altera a Lei no 9.605, de 12 de fevereiro de 1998; e dá outras providências. Diário Oficial da União, Brasília, 03 ago. 2010. Disponível em: <http://www.planalto.gov.br/ccivil_03/_ato2007-2010/2010/lei/112305.htm>. Acesso em: 29 jul. 2020.

Brasil (2014). Óleo de cozinha pode ser descartado de forma consciente. Portal Brasil. 2014. Disponível em: <http://www.brasil.gov.br/meio-ambiente/2014/08/oleo-de-cozinha-pode-serdescartado-de-forma-consciente>. Acesso em: 7 fev. 2017

Bucklin, L. P. (1965). Postponement, speculation and the structure of distribution channels. Journal of marketing research, 2(1), 26-31.

Çelebi, D. (2015). Inventory control in a centralized distribution network using genetic algorithms: A case study. Computers \& Industrial Engineering, 87, 532-539.

Das, C., \& R. Tyagi (1997). Role of inventory and transportation costs in determining the optimal degree of centralization. Transportation Research Part E: Logistics and Transportation Review, 33(3), 171-179.

De Brito, M. P., \& Dekker, R. (2004). A framework for reverse logistics. In Reverse logistics (pp. 3-27). Springer, Berlin, Heidelberg.

Dekker, R., et al., (Eds.). (2013). Reverse logistics: quantitative models for closed-loop supply chains. Springer Science \& Business Media.

Ferri, G. L., Chaves, G. L. D., \& Ribeiro, G. M. (2015) Análise e localização de centros de armazenamento e triagem de resíduos sólidos urbanos para a rede de logística reversa: um estudo de caso no município de São Mateus, ES. Revista Produção, 25(1), $27-42$.

Eynan, A. (1999). The multi-location inventory centralization problem with first-come, first- 

logística reversa com níveis de capacidade. Brazilian Journal of Production Engineering, 6(7), 1-22.

served allocation. European Journal of Operational Research, 114(1), 38-49.

García-Dastugue, S. J., \& Lambert, D. M. (2007). Interorganizational time-based postponement in the supply chain. Journal of Business Logistics, 28(1), 57-81.

Gaur, S., \& Ravindran, A. R. (2006). A bi-criteria model for the inventory aggregation problem under risk pooling. Computers \& industrial engineering, 51(3), 482-501.

Gonçalves, M. F. S. (2015) Planejamento da logística reversa do óleo residual de fritura para uma destinação ambientalmente correta. 112p. Dissertação (Mestrado em Engenharia de Produção) - Departamento de Engenharia e Tecnologia da Universidade Federal do Espírito Santo, São Mateus.

Graves, S. C., \& S. P. Willems, (2000). Optimizing strategic safety stock placement in supply chains. Manufacturing \& Service Operations Management, 2(1), 68-83.

IBGE (2010). Cidades. Disponível em: <http://www.cidades.ibge.gov.br/xtras/perfil.php?lang=\&codmun=320530>. Acesso em: 29 jul. 2020.

IBM (2012). IBM ILOG CPLEX v12.6: User's manual for CPLEX.

Jabali, O. et al. (2012). Analysis of travel times and CO2 emissions in time-dependent vehicle routing. Production and Operations Management, 21(6), 1060-1074.

Kutanoglu, E., \& D. Lohiya (2008). Integrated inventory and transportation mode selection: A service parts logistics system. Transportation Research Part E: Logistics and Transportation Review, 44(5), 665-683.

Lau, H. S., \& A. H. L. Lau (1996). The newsstand problem: A capacitated multiple-product single-period inventory problem. European Journal of Operational Research, 94(1), 29-42.

Leite, P. R. (2002). Logística reversa: nova área da logística empresarial. Revista Tecnologística.

Leite, P. (2009). Logística Reversa: Meio Ambiente e Competitividade, 2003. São Paulo: Editora Ciência Moderna Ltda.

Madalozo, J. A. (2008) O potencial de uso do rejeito de óleo vegetal para produção de biodiesel em Ponta Grossa - PR. 98p. Dissertação (Mestrado em Gestão Territorial) - Setor de Ciências Exatas e Naturais da Universidade Estadual do Paraná, Ponta Grossa, 2008.

Meade, L., et al., (2007). The theory and practice of reverse logistics. International Journal of Logistics Systems and Management, 3(1), 56-84.

Melo, M. T., et al., (2009). Facility location and supply chain management-A review. European journal of operational research, 196(2), 401-412.

Nozick, L. K., \& Turnquist, M. A. (2001). Inventory, transportation, service quality and the location of distribution centers. European Journal of Operational Research, 129(2), 362-371.

Pires, S. (2004). Gestão da cadeia de suprimentos: conceitos, estratégias, práticas e casos. $2^{\text {a }}$ edição. São Paulo: Editora Atlas.

Pitta Junior, O. et al. (2009). Reciclagem do óleo de cozinha usado: uma contribuição para aumentar a produtividade do processo. In Internacional Workshop Advances In Cleaner Production (Vol. 2, pp. 1-10).

Porto, M. M. (2007). Portos e o Desenvolvimento. Aduaneiras.

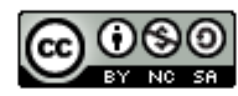



logística reversa com níveis de capacidade. Brazilian Journal of Production Engineering, 6(7), 1-22.

Razmi, J., Zahedi-Anaraki, A., \& Zakerinia, M. (2013). A bi-objective stochastic optimization model for reliable warehouse network redesign. Mathematical and Computer Modelling, 58(11-12), 1804-1813.

Servare Junior, M. W. J., \& P. A. Cardoso (2016). Time postponement in supply chain: a mathematical programming review. Anais do $23^{\text {rd }}$ European Operations Management Association Conference, EUROMA, Trondheim.

Servare Junior, M. W. J., et al., (2018). Mathematical model for supply chain design with time postponement. Transportes, 26(4), 1-15.

Vitória (2011). Censo Demográfico da Prefeitura Municipal de Vitória. Disponível em: <http://legado.vitoria.es.gov.br/regionais/Censo_2010/Tab3_sinopse_pop.asp>. Acesso em 5 fev. 2017

Vitória (2014a). Projeto de Lei ${ }^{\circ}$ 308, de 13 de outubro de 2014. Estabelece a obrigatoriedade aos estabelecimentos comercializadores de óleo de cozinha, especificamente mercados e supermercados, acima de 50 metros quadrados de área destinada ao consumidor, a manter em local visível e de fácil acesso, recipiente especial para o seu descarte. Câmara Municipal de Vitória, ES, 13 out. 2014a. Disponível em: <http://www.cmv.es.gov.br/Arquivo/Documents/PL/PL3082014.pdf>. Acesso em 9 jan. 2017.

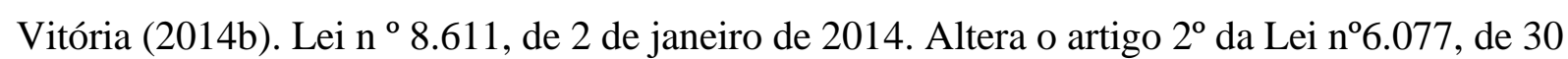
de dezembro de 2003. Câmara Municipal de Vitória, ES. Disponível em: <http://sistemas.vitoria.es.gov.br/webleis/Arquivos/2013/L8611.PDF>. Acesso em: 29 jul. 2020. 